\title{
A AUTOMAÇÃO
}

E O
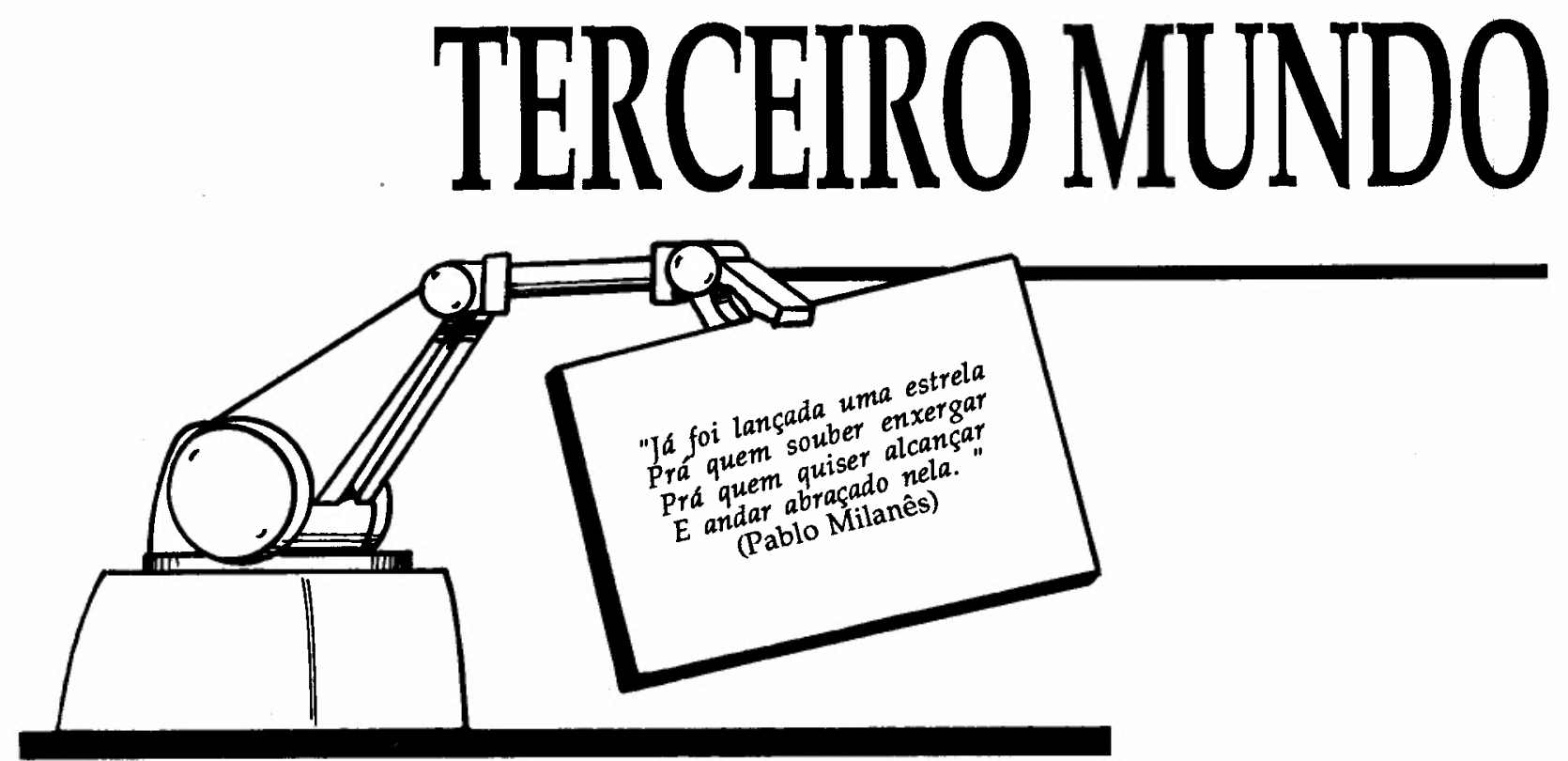

\section{- ANGELO dos SANTOS SOARES}

Engenheiro de Produção pela Escola de Engenharia de São Carlos/USP e Mestrando em Administração de Empresas pela PUC-SP.

- Trabalho apresentado no XX CONGRESSO NACIONAL DE INFORMÁTICA.

\section{INTRODUÇÃO}

E stamos passando por um período de reorganização da Economia Mundial. Muitos foram os fatores que entraram em cena, fazendo com que as teorias econômicas existentes acabassem por não fornecer "modelos" prontos e concluídos, para podermos interpretar a realidade econômica, a nível mundial.

Um dos fatores que acreditamos tenha, de maneira significativa, colaborado para essa "desordem econômica" foi o aparecimento das tecnologias da informação. Chamo de tecnolo- gias da informação a biotecnologia, as telecomunicações, a informática e seus desdobramentos a automação, a robótica, a burótica, o videotexto, etc.

As tecnologias da informação compõem parcela importante dentro do mundo contemporâneo, sendo que essa importância vem se tornando mais acentuada nos últimos anos, com o desenvolvimento da microeletrônica. Essas tecnologias vêm introduzindo mudanças que são capazes de alterar tendências já existentes. Isto é o que pretendemos mostrar nesse trabalho; mais especificamente, como a automação, uma das tecnologias da informação, tem influenciado a economia mundial contemporânea, e em particular a economia dos países do Terceiro Mundo.

\section{AUTOMAÇÃO}

Primeiramente, devemos deixar claro o que entendemos por automação. A automação, para nós, é uma mudança na filosofia da produção, 
como foi dito por John Diebold, um dos primeiros autores a falar sobre ela nos EUA. "Com a automação - creio que este seja talvez o sentido fundamental da automação - estamos começando a ver nosso processo industrial como sistemas completos $e$ integrados, desde a introdução da matéria-prima até ao acabamento no produto final. Este pode ser um produto fisico ou (num processo comercial) uma informação."(1)

Neste sentido, a automação gera a necessidade de mudanças profundas no processo de produção (mudança de lay-out, do desenho do produto, de processos a fim de se permitir a integração), ou seja, com a automação ocorre uma transformação de toda a produção.

Além disso, a automação também permite o aparecimento de novos produtos, como por exemplo, as centrais nucleares, pois ninguém poderia controlar a temperatura tão sensivel, dentro da parte central de um reator. Num sentido mais específico, poderíamos definir a automação como sendo: "toda operação contínua $e$ integrada de um sistema racionalizado de produção que utiliza equipamentos eletrônicos, ou de outro tipo, para regular e coordenar a qualidade e a quantidade da produção"(2).

Cabe aqui ressaltar que, com os avanços da microeletrônica, permitindo a miniaturização dos componentes elétricos, houve uma redução significativa nos custos de processamento das informações, propiciando o aparecimento, basicamente, de quatro tipos de inovações, que permitiram o desenvolvimento e a expansão da automação. Essas quatro inovações, consideradas por nós, neste trabalho, são: os robôs, as máquinas-ferramenta com controle numérico (MFCN), os microcomputadores e os equipamentos CAD-CAM (CAD-Computer Aided Design e CAM-Computer Aided Manufacturing).

Os robôs permitem a substituição da mão-deobra de maneira eficiente, pois não possuem barreiras no que diz respeito à resistência física no seu trabalho. Além disso, eles adicionam uma maior flexibilidade ao capital fixo da empresa e geram um aumento na qualidade do produto.

As MFCN proporcionam um aumento na produtividade, economizam tempo de maquinaria, proporcionam a fabricação de novos produtos, mais complexos, além de possibilitarem o processamento em pequenos lotes de forma mais automatizada. Somada a todos esses fatores, temos a dispensa da intervenção de oficiais mecânicos, uma mão-de-obra altamente qualificada, que era necessária para operar as máquinas-ferramenta universais.

Os computadores, seus terminais, bem como os microcomputadores viabilizam, basicamente, a automação dos escritórios, também conhecida como burótica, através dos processadores de texto, planilhas eletrônicas, sintetizadores de voz, a automação bancária e do comércio, através da simplificação de operações rotineiras e padronizadas.

Finalmente, os equipamentos CAD-CAM representam " $a$ aplicação integrada da tecnologia computadorizada na engenharia e na produção, a partir de uma base de dados comum para peças, produtos $e$ informaçōes relacionadas, tornando mais fácil a transformação de uma idéia criativa em um produto final, a custos reduzidos. O CAD permite definir a forma de uma peça, analisar tensões mecânicas e outros fatores (...). Combinando CAD com o sistema CAM, o usuário pode manipular dados não-gráficos, tais como listas de materiais, custos e outros"(3).

Como funções do CAD temos: elaboração do projeto e sua modelação geométrica, análise de engenharia, desenho e cinemática. E como funções do CAM, podemos citar: projeto de ferramentas, o controle das máquinas, o planejamento de processos e de materiais, robótica e a administração da unidade fabril.

A partir do CAD-CAM, foi possivel o desenvolvimento do ICAM (Integrated Computer Aided Manufacturing), cujo objetivo último é a aplicação de um sistema de fabricação integrado numa unidade produtiva completamente automatizada.

Todas essas inovações fazem com que nenhuma "face" da economia seja deixada para trás, sem ser alterada pois, tanto na esfera da produção, como na esfera da circulação, as mudanças geradas pela automação atuam, basicamente, nos padrőes de qualificação e na produtividade do trabalho e dessa forma, inserem na economia, seja a nível nacional ou mundial, os novos padrões de concorrência capitalista.

A flexibilidade que a nova tecnologia proporciona é importantíssima para minorar o desequilíbrio entre ritmos de trabalho das diversas partes da produção e o tempo de engajamento das peças nas máquinas: "com melhor equi-

1. SANTOS, Theotonio dos. Revolução científicotécnica e capitalismo contemporâneo. Petrópolis, R. J., Editora Vozes, 1983, p. 28.

2. Idem, ibidem, p. 30.

3. RATTNER, Henrique. Informática e Sociedade. São Paulo, Brasiliense, 1985, pp. 128-129. 
líbrio proporcionado à linha de produção e com melhor taxa de utilização das máquinas, os tempos mortos em que o Capital (Fixo e Circulante) está-se desvalorizando inutilmente, tendem a ser reduzidos de maneira drástica."(4)

\section{A AUTOMAÇÂO E O TERCEIRO MUNDO}

Dentro do atual "quadro térico" da economia mundial, há uma forte tendência em admitir a transnacionalização da economia como um fato irreversível, que dia a dia avança mais e mais, a ponto de se questionar a existência dos Estados-Nações e sua respectiva perda de poder frente às empresas transnacionais (ETN).

Segundo Michalet, "o que o fenômeno das ETN designa, a nível da aparência, é a instauração de uma Nova Ordem Internacional"(5). Trata-se de um "novo sistema onde a atividade industrial se estende até regiōes outrora agrícolas ou de exploração mineral." (6)

Ainda segundo o autor em questão, esse processo é o resultado, "sobretudo, da impossibilidade encontrada pelas economias mais desenvolvidas, a começar pela economia americana, em manter no interior de suas fronteiras políticas a totalidade do processo de formação do valor (...). Na medida em que o alto nível de desenvolvimento das forças produtivas torna problemático o aumento da taxa de mais-valia relativa, a saída consiste em procurar regiōes onde a taxa de mais-valia é mais elevada. Tratase, pois, de deslocar o processo produtivo para regiões menos desenvolvidas, sem prejuízo de seu controle"().

Hoje, o que podemos observar é que, com o desenvolvimento, em ritmo nunca visto, da microeletrônica e, como uma conseqüência desse fato, um aumento na velocidade da automatização da sociedade, a procura de "regiōes onde a taxa de mais-valia é mais elevada" acabou por se tornar uma "coisa do passado", pois a automação propicia um aumento substancial na taxa de mais-valia. Vejamos por quê.

Segundo Marx, a taxa de mais-valia relativa é aquela que resulta da "redução do tempo de trabalho $e$ da correspondente mudança da proporção entre os dois componentes da jornada de trabalho"(8). O aumento da taxa da mais-valia relativa se dá em virtude do acúmulo de inovações técnicas, que aumentam a produtividade do trabalho, diminuindo o valor dos bens de consumo nos quais se traduz a força de trabalho, e assim, diminuindo o tempo de trabalho para a reprodução dessa força de trabalho. "Uma alteração no processo de trabalho, pela qual se reduz
- tempo de trabalho socialmente necessário para produzir uma mercadoria."(9)

A automação, composta basicamente pelos robôs, MFCN, microcomputadores e CAD-CAM, produz um aumento na taxa de mais-valia relativa, aumentando a produtividade, alterando os processos de trabalho. Houve a "superação" dos limites físicos dos seres humanos. Os trabalhadores que têm de controlar as máquinas passam a trabalhar em turnos, como no século XVIII, e o trabalho noturno passa a ser encarado, novamente, como sendo um "gesto natural" para parafrasear Caetano Veloso. $\mathrm{O}$ aumento da jornada de trabalho pode ser visto, claramente, nesta passagem sobre a indústria japonesa FANUC, que produz robôs de forma automatizada, no Japão: "Dentro do gigantesco hangar, as máquinas se desenvolvem apenas pelos seus movimentos $e$ o calor provoca o funcionamento dos seus cérebros computadorizados. Elas não param. Trabalham todos os dias, 24 horas."(10)

Assim sendo, a busca de taxas de mais-valia relativa mais elevadas, nas regiões menos desenvolvidas, que segundo Michalet era a saída para as economias mais desenvolvidas continuarem o seu processo de formação do valor, com a automação, perde a sua razão de ser, pois o aumento da taxa de mais-valia, propiciado pela automação, volta a possibilitar a criação de valor dentro das próprias economias mais desenvolvidas.

Desta forma, se "o processo de multinacionalização é uma manifestação desse movimento" de procura de taxa de mais-valia relativa mais elevada, em regiões menos desenvolvidas, o que a automação traz consigo é um movimento de "desmultinacionalização" da economia mundial.

4. TAUILLE, José R. "Aspectos sociais da automaçăo no Brasil", in Organizaçāo, Trabalho e Tecnologia. São Paulo, Editora Âtlas, 1986, p. 22.

5. MICHALET, Charles-Albert. O Capitalismo Mundial. Rio de Janeiro, Paz e Terra, 1984, p. 250.

6. Idem, ibidem, p. 251.

7. Idem, ibidem, idem.

8. MARX, Karl. O Capital. Vol. I. Săo Paulo, Abril Cultural, 1983, p. 251.

9. Idem, ibidem, idem.

10. TERZANI, Tiziano. "Aqui, robôs fabricam o futuro" in: Jornal da Tarde, 13.09.86 - Traduzido do Der Spiegel por Rodolpho Krestan. 
Segundo Michalet, entretanto, as novas "zonas de implantação não foram escolhidas com a única preocupação de elevar a taxa de extração de mais-valia"(11), mas também trata-se de resistir às novas condições de concorrência.

Aqui, também, a automação derruba esse argumento pois, como já dissemos, a automação implica, diretamente, em alterações nos padrões de qualificação e produtividade do trabalho e, portanto, redefine os padrões de concorrência capitalista. Não automatizar pode significar perder a competitividade, seja a nível nacional ou mundial.

A automação das plantas industriais no Primeiro Mundo ainda resolve um outro problema, que é o da localização das empresas onde a taxa de mais-valia é mais elevada, mas tem, como ponto negativo, o baixo poder aquisitivo da população. Automatizando-se as empresas do Primeiro Mundo, teremos o aumento da taxa de mais-valia, como já vimos anteriormente, num local onde o poder aquisitivo da população é alto.

Com isso, o que observamos hoje é que, ao invés da crescente transnacionalização da economia mundial, apontada por Michalet e outros autores, temos uma retransferência das ETN para os seus países de origem. "Algumas empresas que eram candidatas em potencial para se transferir para os países em desenvolvimento, serão capazes, agora, de sobreviver nos países desenvolvidos com a ajuda da automação."(12)

Segundo Gerd Junne, essa retransferência se deve, basicamente, aos seguintes fatos:

- Os equipamentos automatizados proporcionam a fabricação de vários produtos finais, através de uma reprogramação dos equipamentos e não de um único produto, como era no passado. Possibilita, também, a produção em pequenos lotes, além de tornar possível a automação de um grande número de tarefas de montagem ( $40 \%$ de toda a mão-de-obra empregada na indústria está nas operações de montagem).

- A automação não muda só o processo da produção, muda também o desenho do produto, para se evitar "gargalos" no processo automatizado. Muitas vezes, o desenho do produto dificulta operações automatizadas.

- Os preços dos equipamentos para automação, no Primeiro Mundo, já estão se tornando mais atrativos, e, em grande parte, padronizados, possibilitando a interligação de equipamentos diferentes em sistemas integrados.

- A crise econômica e a alta taxa de desemprego têm enfraquecido os sindicatos nos países do Primeiro Mundo, fazendo com que eles acei- tem, por exemplo, o trabalho em turnos, que antes não era aceito. Nesse caso, torna-se mais atrativo ainda automatizar a produção, pois os equipamentos são mais caros, exigem uma mãode-obra mais especializada (que não é encontrada facilmente no Terceiro Mundo) e assim os equipamentos podem ser amortizados mais rapidamente.

- O período de treinamento da mão-de-obra, no Primeiro Mundo, para a utilização dos robôs, de CAD-CAM e outros equipamentos, já passou e desta forma, portanto, lá já se possui uma mão-de-obra especializada e treinada para usar, de forma intensiva, todos os equipamentos que propiciam a automação. Esse treinamento é importante, pois é necessário saber como manusear os equipamentos, como fazer a sua manutenção e como integrá-los no sistema de produção. Assim sendo, o Primeiro Mundo já está apto a usar, mais extensivamente e mais intensivamente, os equipamentos que propiciam a automação.

- Existe, ainda, o que se convencionou chamar de "ilhas de automação", que é a automação setorizada. Entretanto, a integração dessas "ilhas" já está acontecendo. O CAD-CAM já é uma realidade. Essa integração vai fazer com que grande parcela de mão-de-obra se torne supérflua, pois várias tarefas que hoje são apenas passagens de informação de um setor para outro setor tendem a desaparecer.

O que podemos observar, também, é que os países do Primeiro Mundo têm sustentado programas de automação em larga escala a fim de aumentar a competitividade de suas indústrias a nível mundial. Temos, como exemplo desses programas de automação, o programa desenvolvido pelo Ministério de Pesquisa e Tecnologia da República Federal da Alemanha a fim de intensificar o uso do CAD na construção de máquinas (que é essencial para a posição da Alemanha Ocidental no mercado mundial). Em 1984 , só $4 \%$ das empresas utilizavam o CAD. Com o programa é esperado que, até o fim de 1988 , cerca de $60 \%$ das empresas estejam utilizando o CAD.

Um outro exemplo de estímulo à automação é o caso da General Motors, que "deverá investir nos próximos 4 anos, 40 bilhoes de dólares na tecnologia de automação integrada na Manufa-

11. MICHALET, Charles-Albert. Op. cit., p. 251.

12. RADA, Juan. The impact of micro-electronics. Geneva, Ilo, 1982, pp. 106-107. 
QUADRO 1

Dlstribulçăo de Robós por Indústria nos EUA a França para 1990

\begin{tabular}{|lr|lr|}
\hline EUA & (por vendas) & FRANÇA & (por unidade) \\
\hline INDÚSTRIA & $\%$ & INDÚSTRIA & $\%$ \\
\hline & & & \\
Manufatura Leve & 39 & Automobilística & 30 \\
Automobilística & 30 & Metal Mecânica & 20 \\
Eletro/Eletrônica & 14 & Eletrônica & 18 \\
Fundiçäo & 11 & Engenharia Mecânica & 15 \\
Manufatura Pesada & 9 & Materiais Cerâmicos/Transformaçāo & 4 \\
& & Material Plástico & 4 \\
\hline
\end{tabular}

Fontes: EUA - Bache Halsey, Stuart Shields

FRANÇA - Diebold Consultants in Industrial Robots OECD, 1983

tura, no sentido de reduzir custos de mão-deobra, incrementar qualidade e produtividade, $e$ competir mais efetivamente no mercado internacional. A instalação da GM em Hamtramck, para a produção de carros de luxo, constitui o estado-da-arte do sistema de automação e gerenciamento industrial."(13)

Nos EUA, o custo total com a mão-de-obra já decaiu de $25 \%$ a $30 \%$ nos últimos 20 anos.

Desta feita, o fator de "caráter dominante" que atraía as ETN a localizarem parte de sua produção no Terceiro Mundo perdeu a sua importância. Além disso, a automação também elimina "os riscos políticos", as "mudanças das fontes de financiamento", "a redução do aporte em dólares" em favor de uma maior participação de capitais locais (leia-se do Terceiro Mundo).

Além dessa retransferência para o Primeiro Mundo, a automação do Primeiro Mundo acaba colocando os países do Terceiro Mundo numa situação bastante vulnerável pois, segundo a OIT - Organização Internacional do Trabalho -, os setores que estão sendo automatizados, em parte, são os mesmos setores nos quais certos países do Terceiro Mundo conseguiram uma maior penetração nos mercados mundiais: têxteis, calçados, vestuário e eletrônica. ${ }^{(14)}$

Essa tendência pode ser observada no Quadro 1, que mostra a distribuição prevista de robôs por indústrias em 1990.

Também pode-se observar essa tendência no Quadro 2, que mostra a distribuição do uso de robôs (segundo o volume de vendas) no Japão em 1980.
QUADRO 2

Distribuiçăo de Robós (por volume de vendas) no Japão om 1980

\begin{tabular}{|lr|}
\hline INDÚSTRIAS & $\%$ \\
\hline Automóveis & 30 \\
Máq. Elétrica & 36 \\
Moldagem de Plástico & 10 \\
Produtos Metálicos & 5 \\
Ferro $\bullet$ Aço & 1 \\
Outros & 18 \\
\hline
\end{tabular}

Fonte: JIRA

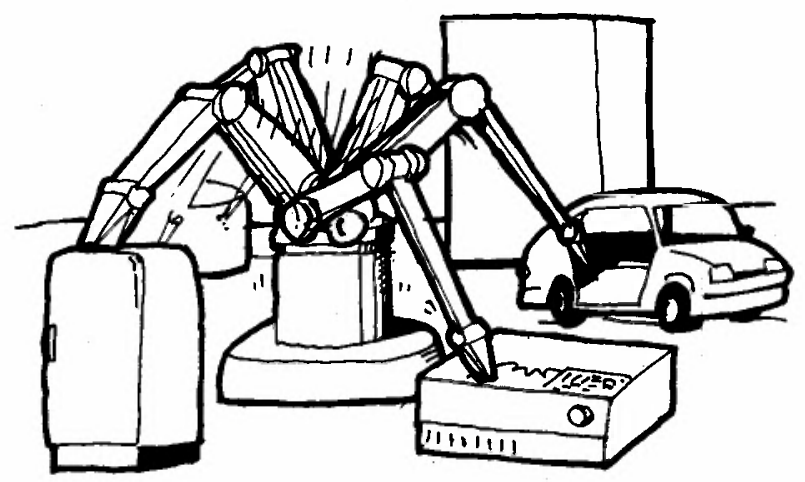

13. DOMINGUES, Antonio L. et alii. "Quais os benefícios da integração de sistemas industriais com CAD/CAM?" in: Anais do $2^{\circ}$ Congresso Nacional de Automação Industrial. São Paulo, 1985, p. 363.

14. OIT. Efectos de las empresas multinacionales sobre el empleo en los paises industrializados. Geneva, 1982, p. 81. 
Segundo Werner Olle(15), o movimento de retransferência do Terceiro para o Primeiro Mundo já pode ser observado e ele cita os seguintes casos:

- Em 1982, a AEG, Telefunken Mexicana, que produzia jogos eletrônicos, foi fechada. Saldo: 800 desempregados.

- Em Taiwan, a BOSCH fechou sua fábrica que produzia lentes para câmeras fotográficas.

- A GRUNDING, em 1983, fechou sua fábrica (Grunding Taiwan Company) em Taiwan, que produzia equipamentos HI-FI e televisores. Saldo: 850 desempregados.

- Em 1984, a produção de material de montagem da BRASILIAN PERLEX PRODUTOS PLÁSTICOS LTDA. foi encerrada no Brasil. Saldo: 200 desempregados.

- Em 1981, em Mauritius, a SIEMENS fechou a sua fábrica de equipamentos eletrônicos. Saldo: 1.000 desempregados.

Em outros países da América Latina, o volume de negócios alemães também tem diminuído, com a redução dos nivieis de produção e de emprego.

No Brasil, esse movimento de retransferência também pode ser observado, embora não se tenha, ainda, associado à automação no Primeiro Mundo. Podemos, por exemplo, constatar o fato da retransferência no depoimento de Paulo Guedes, Vice-Presidente da IBMEC (Instituto Brasileiro de Mercado de Capitais): "Há inúmeros exemplos de estrangeiros que se retiraram. A MBR, comprada pela CAEM, do Grupo Antunes; a US Steel, que vendeu a BrazaçoMapri; a Westinghouse, que repassou uma de suas indústrias ainda na planta; a ESSO e a IBM, que enxugaram seu horizonte de participações em novos negócios"(16). Nas justificativas do $\mathrm{Sr}$. Paulo Guedes, a automação no Primeiro Mundo não é mencionada, mas acreditamos que esse fato tenha exercido influência nas decisões dessas empresas.

Essa retransferência para o Primeiro Mundo trará sérios problemas para os países do Terceiro Mundo. $O$ desemprego aparece em primeiro lugar, pois, além do desemprego causado pela partida dessas empresas, os países do Terceiro Mundo possuem um desemprego estrutural, o que provocará uma enorme "massa de desempregados".

Todavia, não é só o problema do desemprego que afeta os países doTerceiro Mundo, e em especial os NIC's - Newly Industrialized Countries - com essa retransferência. De acordo com relatório da ONU, ao desativarem as suas linhas de produção, geralmente as ETN não deixam nada no país hospedeiro, em termos de tecnologia. Esse fato já foi constatado nas Filipinas quando da desativação da SIGNETICS que, por não ter desenvolvido, naquele país, $o$ ciclo tecnológico completo, não deixou nada para o país hospedeiro em termos de tecnologia. Deixou apenas o desemprego. Fato semelhante aconteceu aqui no Brasil, quando a IBM deixou de fabricar discos magnéticos para computadores, desativando a sua linha de produção. Passados alguns anos, quando a indústria brasileira veio a precisar desse insumo, não se encontrou, no País, ninguém que dominasse essa tecnologia.

Deste modo, a retransferência do Terceiro Mundo para o Primeiro, devida à automação, traz para o Terceiro Mundo, e principalmente para os NIC's, o desemprego em massa, a perda da tecnologia pseudotransferida e uma possível perda da competitividade no Mercado Mundial, em virtude de a automação no Primeiro Mundo estar se localizando principalmente em áreas onde esses países conseguiram uma certa competitividade. Este fato parece-nos uma justificativa plausivel para que os NIC's tenham adotado mecanismos de proteção e estímulo à produção interna das tecnologias da informação. Cabe, aqui, ressaltar que esses mecanismos variam de país para país.

Segundo John Martinussen, da Universidade de Roskilde, na Dinamarca, "as condiçōes da transferência de tecnologia, hoje, dependem muito do pais que vai recebê-la. Dependem da pesquisa e da capacidade de desenvolvimento do pais hospedeiro. Quanto melhor a tecnologia for entendida, melhores condições de barganha existirão" (17).

Sendo assim, se os países do Terceiro Mundo não tentarem se proteger, para poderem desenvolver suas próprias tecnologias da informação, e caso ainda não consigam se desenvolver nessa área (o que pode acontecer), o que vai ocorrer é um aumento do gap existente entre o Primeiro e

15. OLLE, Werner. "New technologies and the international division of labour: retransfer of foreign production from developing countries?" in Vierteljahres Berichte - Problems of International Cooperation. Stuttgart, $n^{2} 103$, Marz 1986, p. 14.

16. NASSAR, José R. "As 'verdinhas' vão se embora" in Revista Senhor. Săo Paulo, Edit. Três, $n^{2} 290$, 07/10/1986, p. 40.

17. JUNNE, Gerd. "New technologies and third world development" in Vierteljahres Berichte Problems of International Cooperation, Stuttgart, $n^{2}$ 103, Marz 1986, p. 08. 
o Terceiro Mundo. Esse gap já existe hoje, dentro do próprio Primeiro Mundo, onde países que não deram a importância devida às tecnologias da informação acabaram por ficar dependentes, principalmente do Japão e dos EUA. É interessante notarmos que esses países, como por exemplo a própria Grã-Bretanha, ficaram mais atrasados, em termos dessas tecnologias, do que - Brasil. Esse atraso tem preocupado seus governantes, como podemos observar nesse depoimento do Advisory Council for Applied Research and Development da Grã-Bretanha: "Se nós negligenciarmos ou rejeitarmos (esta tecnologia) como uma Nação, o Reino Unido vai se juntar aos países subdesenvolvidos." (18) $\mathrm{O}$ mesmo tipo de preocupação também pode ser observado na França, que também está atrasada em tecnologias da informação.

A automação do Primeiro Mundo, desta forma, parece-nos ser uma das razões mais importantes para que os NIC's tentem desenvolver alguma tecnologia própria, pois se vivemos um momento de reorganização da economia mundial, na iminência de uma nova divisão internacional do trabalho, os NIC's devem aproveitar-se deste momento de reordenação para imprimirem novos rumos tecnológicos e econômicos às suas sociedades.

Lembrando Martin Carnoy, acreditamos que "as novas técnicas não são deterministas: têm criado novas condições para as empresas e para a política das autoridades, mas também têm criado novas possibilidades. Neste contexto, as diversas políticas macroeconômicas e de organização darão origem a resultados distintos para a mão-de-obra $e$ as direções das empresas. As sociedades que compreenderem essas possibilidades $e$ as aproveitarem em harmonia com a situação local pagarão custos sociais mais baixos $e$ obterão os maiores proveitos que as novas técnicas são capazes de oferecer. As sociedades que não conseguirem fazer isso se verão subjugadas pelas novas técnicas."(19)

Não se trata de um isolamento, que é inviável nos dias de hoje, nem tampouco de se igualar aos conglomerados ou aos países do Primeiro Mundo na corrida atrás de inovaçōes, pois sabemos que "cada sociedade cria sua técnica e seu tipo de saber, bem como também seu tipo de transmissão de saber"(20). Trata-se, isto sim, de uma "recusa do servir" para utilizarmos La Boetie, que não pode ser acusado de um "nacionalismo ingênuo", pois escreveu o seu Discurso da Servidão Voluntária por volta de 1548, muito antes do aparecimento dos EstadosNações, e também por ser um crítico contun- dente do Estado.

A "recusa de servir" aparece como resposta à seguinte pergunta: "Como é possivel que tantos homens, tantas cidades, tantas naçōes às vezes suportem tudo de um tirano só, que tem apenas o poderio que lhe dão, que não tem o poder de prejudicá-los, senão enquanto aceitam suportálo $e$ que não poderia fazer-lhes mal algum se não preferissem, a contradizê-lo, suportar tudo dele"(21), ou seja, como "um" pode dominar "muitos"?

Para esta pergunta, La Boetie propõe, não o rompimento da relação dominante/dominado, mas a recuperação da liberdade através do "nãoservir", como afirma na seguinte passagem: "Decidi não mais servir $e$ sereis livres. Não quero que o enfrenteis nem o abatais; somente não mais o sustenteis e o vereis, como um grande colosso, a quem subtraiu-se a base, a cair com seu próprio peso e quebrar-se"(22).

Portanto, quando os países do Terceiro Mundo, principalmente os NIC's, tentam proteger as suas indústrias de Tecnologia de Informação, não se trata de "nacionalismo ingênuo". Tratase de uma tentativa de recuperar a liberdade. Trata-se de recusar a servidão voluntária.

É certo que nessa "nova divisão" alguns países alcançarão a sua liberdade e outros não, pois as medidas de proteção de suas indústrias são diferentes, de país para país. Quem escolheu a melhor opção? Qual NIC se sairá melhor? Qual NIC recuperará a sua "liberdade"? Qual NIC vai "abraçar e apertar com as duas mãos" a servidão? Ainda não se pode responder a estas perguntas; podemos, apenas, dizer: "Já foi lançada uma estrela/Prá quem souber enxergarl Prá quem quiser alcançar/E andar abraçado nela"..

18. RADA, Juan. Op. cit., p. 70.

19. CARNOY, Martins. "Efectos de las técnicas más avanzadas en los mercados internacionales del trabajo" in Revista Internacional del Trabajo, Geneva, OIT, vol. 105, n 1, Enero-Marzo de 1986, pp. 50-51.

20. CASTORIADIS, C. \& COHN-BENDIT, D. Da Ecologia a Autonomia, São Paulo, Brasiliense, 1981, p. 13 .

21. LA BOETIE, Etienne de. Discurso da servidão voluntária. São Paulo, Brasiliense, $2^{\text {a }}$ edição, 1982, p. 13.

22. Idem, ibidem, p. 79. 